\title{
Cannabis consumption and risk of developing schizophrenia: myth or reality?
}

\author{
MARTA DI FORTI and ROBIN McGREGOR MURRAY
}

\section{BACKGROUND}

Cannabis is one of the most popular recreational drugs. The rates of use and dosage, based on the levels of active compounds present in street drugs, is thought to be climbing in the UK and Europe; $40 \%$ of 15 years olds in the UK are thought to have tried the drug. There is no dispute that cannabis intoxication can cause brief psychotic episodes or short-term relapse of pre-existing psychotic symptoms (Negrete et al.,1986; Thornicroft, 1990; Mathers \& Ghodse, 1992). More worryingly, during the past few years a number of studies have indicated that exposure to cannabis is associated with cognitive impairment and the risk (about two fold) of developing psychosis (Ashton, 2002; Iversen, 2003; Arseneault et al., 2004).

It is quite surprising that it has taken more than fifteen years to produce public health interest in the association between one of the most widely used psychotropic drugs and one of the most devastating of mental illnesses. In 1987 Andreasson described an association between cannabis use and onset of psychosis (Andreasson et al.,1987). This landmark cohort-study of 45,000 Swedish male conscripts (representing 97 percent of men age 1820 in the population at that time) and a 15-year follow up, found that heavy use of marijuana at age 18 increased the risk of schizophrenia later in life by six times. There was a dose-response relationship between cannabis use at age eighteen and schizophrenia diagnosis 15 years later.

Address for correspondence: Dr. M. Di Forti. Division of Psychological Medicine. PO63. Institute of Psychiatry. De Crespigny Park. Denmark Hill, London SE5 8AF (United Kingdom) .

Fax: +44-207-7019044

E.mail: m.diforti@iop.kcl.ac.uk

Declaration of interest: none
However only $3 \%$ of conscripts heavy cannabis users went onto develop schizophrenia, suggesting that cannabis might exert its causal role only in already vulnerable individuals.

\section{RECENT STUDIES}

In 2002, Zammit conducted a follow-up of the same Swedish Conscript Cohort (Zammit et al. ,2002). Heavy cannabis users were 6.7 times more likely than non-users to be diagnosed with schizophrenia later in life. The same risk was described in a sub-sample of conscripts who only smoked cannabis as opposed to using other drugs as well. Zammit challenged the self-medicating hypothesis that explains the association between cannabis and schizophrenia as a consequence of prodromal manifestation of psychosis. He repeated the analyses on those individuals who developed schizophrenia only 5 years later after conscription. He found no difference between the results obtained and those from the entire cohort. Therefore he concluded that this study supported a causal role for cannabis in the onset of schizophrenia.

Jim Van Os conducted analyses of the Netherlands Mental Health Survey and Incidence Study (NEMESIS) examining the effect of cannabis use on psychotic symptoms among the general population (Van Os et al., 2002). In this study, 4045 psychosis- free and 59 subjects with self reported symptoms of psychosis were assessed at baseline, and then at one year and three years follow up. Even after statistical adjustment for factors including ethnic group, marital status, educational level, urbanicity and discrimination, the individuals using cannabis at baseline were three times more likely to report psychotic symptoms at follow up. The short interval between baseline and follow-up assessment does not allow one to ver- 
ify a temporal priority in the association between cannabis and psychosis. However. the results confirm that cannabis is an independent risk factor for the onset of psychosis in previously healthy individuals and that cannabis use is associated with poor outcome in individuals with an established psychosis vulnerability.

In the Christchurch Health \& Development Study in New Zealand, a birth cohort of 1055 children studied annually throughout childhood, data on cannabis use and psychotic symptoms ( 10 items from the SCL-90) were collected at ages 18,21, 25 (Fergusson, 2003; Fergusson et al., 2005). Cannabis use had a positive and significant effect on psychotic symptoms $(\mathrm{p}<0.001)$ implying that increasing cannabis use was associated with increasing symptoms levels. The effect of psychotic symptoms was negative; if anything the development of these symptoms may have inhibited rather than encouraged cannabis use.

Similarly, a general- population birth cohort of 1034 children born in Dunedin, New Zealand, in 1972-1973 was assessed 10 times from age 3 . At age 11 , they were interviewed by a child psychiatrist, and at ages 15 and 18 they were asked about drug consumption. At age 26, 96\% were interviewed using a standardized psychiatric interview schedule yielding Diagnostic and Statistical Manual of Mental Disorders (DSM IV) and 3.7\% met criteria for schizophreniform psychosis (Arseneault et al., 2002). Study participants who used cannabis at age 15 and 18 reported higher rates of psychotic symptoms at age 26 compared to non-users. Furthermore, $10 \%$ of the age 15 cannabis smokers in the Dunedin cohort were diagnosed with schizophreniform disorder at age $26 \mathrm{com}$ pared with $3 \%$ of the non-using control group. This study also elegantly indicates "specificity of outcome": cannabis use by age 15 did not predict depressive outcomes at age 26 and "specificity of exposure": the use of other illicit drugs in adolescence did not predict schizophreniform outcomes over and above the effect of cannabis use (Arseneault et al., 2002).

Some criticism though can be made of the above studies. Their lack of homogeneity of measures of schizophrenia outcome make it difficult to draw a firm conclusion on schizophrenia from the findings reported. However they all consistently show that cannabis users have an elevated risk for psychosis later in life. Another limitation derives from the fact that measures of cannabis use were based on self-report and not supplemented by urine tests or hair analyses. The Dunedin study is the only study to date to clearly establish temporal priority between cannabis use and adult psychosis.

Some have claimed that these studies may be confounded by the effect of stimulant drug use such as amphetamines, phenylcycline and LSD which are thought to be psychotogenic (Murray et al., 2003); use of other drugs among young adults is almost always preceded by cannabis consumption (Fergusson \& Hardwood, 2000). Nevertheless the evidence for the association between cannabis use and later schizophrenia in the Dunedin. NEMESIS and Swedish studies held even when adjusting for the use of other drugs (Arseneault et al., 2002; Van Os et al., 2002; Zammit et al., 2002).

A further contribution to the understanding of the association between cannabis use and schizophrenia comes from "High-Risk Studies". An analyses of the Edinburgh High-Risk study reported that both individuals at high genetic risk of schizophrenia (with two affected relatives) and individuals with no family history of schizophrenia were at increased risk of psychotic symptoms after cannabis use (Miller et al., 2001).

\section{MECHANISM}

The above epidemiological studies indicate that cannabis use is a risk factor for schizophrenia, and that the association appears stronger if individuals are exposed to cannabis in early adolescence suggesting a developmental effect. But how could cannabis cause psychosis? The endocannabinoid system modulates neurotransmitter systems including GABAergic, dopaminergic, and glutamaergic systems, all potentially involved in the aetiology of psychosis. Evidence of a modulating role of cannabinoids in neurotransmitters release is compatible with the pre-synaptic rather than post- synaptic predominant location of the $\mathrm{CB} 1$ cannabinoid receptors. In both animal and human brain, $\mathrm{CB} I$ receptors are found in high densities in the limbic forebrain, particularly the hypothalamus and the anterior cingulated cortex, and in the hippocampus (Herkenham et al.,1991; Elphick \& Egertova, 2001), cortical areas thought to be implicated in the pathophysiology of schizophrenia.

Pharmacological studies with cannabis or delta-9-tetrahydro-cannabinoid (THC) in humans have examined the specific psychotogenic effect of cannabis. D'Souza et al. (2004) in a double blind, placebo to schizophrenia cases and healthy volunteers. Controls with a family history of psychiatric disorders were excluded, and both cases and controls with a current history of substance misuse other than nicotine were excluded. Subjects were randomly administered 2.5 or $5 \mathrm{mg}$ of delta-9-THC or the placebo intravenously (over 2 minutes). The assessment of psychotic symptoms was carried out using standardized interviews such as the PANSS. They also assessed mood 
state before and several times after the drug administration. 10-20 minutes after delta-9-THC administration both stable medicated patients with schizophrenia and healthy volunteers presented transient increase of schizophrenialike positive and negative symptoms: resolving within a four hours observation period.

Most interestingly, schizophrenia patients reported an exacerbation of positive symptoms unique to their illness presentation (e.g. patients with predominantly persecutory delusions reported more persecutory delusion after delta-9-THC administration), and healthy controls reported a full range of schizophrenia like symptoms. Healthy volunteers also showed a dose-related effect of delta-9THC on immediate and delayed word recall, sparing recognition recall, impaired performance on tests of distractibility, verbal fluency, working memory; increased plasma cortisol was associated with anxiety and euphoria. However, the delta-9-THC doses employed in this study are much higher than those typically present in herbal cannabis preparation, and this may have been exaggerated by the intravenous mode of administration, resulting in faster delivery and higher brain concntrations than is typically achieved by recreational users. This study, although consistent with most of the current literature associating cannabis and schizophrenia raise questions about their social relevance and generalizibility.

Chronic cannabis use (Solowij et al., 2002; Lindqvist et al., 2001; Block et al., 2002) has been associated with deficits in prefrontal cortex functions, such as impaired memory and attention, which are also found in schizophrenia (Bunney \& Bunney, 2000; Weinberger et al., 2001). These effects are potentially mediated through diminished dopamine transmission in the prefrontal cortex (Egan et al., 2001; Verrico et al., 2003. Decreased frontal dopamine is known to be associated with a reciprocal increase in meslimbic dopamine, and Voruganti et al. (2001) showed, by accident in one subject, that smoking cannabis caused a $20 \%$ decrease in striatal D2 receptor binding "suggestive of increased synaptic occupancy" and increased mesolimbic dopamine activity, a mechanism implicated in hallucinations and delusions. In rats, Tanda et al. (1997) showed that intravenous THC increases extra cellular dopamine in the shell of nucleus accumbens. In 1999 Gorriti et al. (1999) studied the effect of amphetamine on rats with and without pre-treatment with THC indicating that chronic treatment with THC induced sensitization to psychomotor effects of amphetamine. This suggests a common effect in dysregulating dopamine systems.

However, there have been relatively few laboratory based and neuroimaging studies so the exact mechanism underlying the capacity of cannabinoids to induce psychosis remains unclear.

\section{VULNERABILITY}

Finally, we are left with the most intriguing question animating the public and scientific debate: Why do only a small proportion of cannabis users develop psychotic symptoms or schizophrenia?

Cannabis does not have severe long term effects for the majority of users, but it is appears that some individuals are more vulnerable to its schizophrenogenic effects than others, and that the timing of use may amplify its effect; use in adolescence seems to be more hazardous. Genetic vulnerability is supported by evidence of a gene by environment $(\mathrm{G} \times \mathrm{E}$ ) interaction between a functional polymorphism in the catechol-O-methyltransferase gene (COMT) and exposure to cannabis. This polymorphism is weakly associated with schizophrenia (Lewis et al., 2003), and the enzyme it produces has an essential role in the breakdown of dopamine in the prefrontal cortex. COMT appears to moderates the influence of adolescent cannabis use on the development of adult psychosis, with a five-fold increased risk of developing schizophreniform disorder in cannabis users with the high activity Val allele (COMT) (Caspi et al., 2005).

\section{CONCLUSION}

The definition of a cause of a disease is an antecedent event, condition or characteristic that is necessary for the occurrence of the disease at the moment it occurred, given that other conditions are fixed (Rothman \& Greenland, 1998).Cannabis is not a necessary cause of schizophrenia in that most individuals with the illness have not smoked it. Neither is cannabis a sufficient cause in that most cannabis users do not develop schizophrenia. However, the available evidence indicates that cannabis acts as a component cause and part of a constellation of causes including genetic predisposition.

\section{REFERENCES}

Andrèasson S.. Allebeck P.. Engstrom A. \& Ryldberg U. (1987) Cannabis and schizophrenia: A longitudinal study of Swedish conscripts. Lancet 26. 1483-1486.

Arsencault L.. Cannon M. \& Poulton R (2002). Cannabis use in adolescence and risk for adult psychosis: longitudinal prospective study. British Medical Journal 325, 1212-1213 
Arsenault L.. Cannon M., Witton J. \& Murray R.M. (2004). Causal association between cannabis and psychosis: examination of the evidence. British Journal of Psychiarry 184. 110-117.

Ashton H. (2002). Cannabis or health? Current Opinion Psychiatry 15. 247-253.

Block R.I.. O'Leary D.S.. Hichwa R.D.. Augustinack J.C., Boles Ponto L.L.. Ghoneim M.M.. Arndt S.. Hurtig R.R.. Watkins G.L.. Hall J.A.. Nathan P.E. \& Andreasen N.C. (2002). Effects of frequent marijuana use on memory-related regional cerebral blood flow. Pharmacology: Biochemistry and Behaviour 72. 237-250.

Bunney W.E. \& Bunney B.G.(2000). Evidence for a compromised dorsolateral prefrontal cortical parallel circuit in schizophrenia. Brain Research Reviews 31, 138-146.

Caspi.A.. Moffitt E.T., Cannon M.. McClay J., Murray R.. Harrington H. L., Taylor A., Arseneault L., Williams B., Braithwaite A., Poulton R. \& Craig I.W. (2005). Moderation of the effect of adolescentonset cannabis use on adult psychosis by a functional polymorphism in the catechol-o-methyltransferase gene: Longitudinal evidence of a gene $X$ environment interaction. Biological Psychiatry 57, 1117 1127.

D'Souza D.C., Perry E., MacDougall L., Ammerman Y., Cooper T., Wu Y.T., Braley G., Gueorguieva R. \& Krystal J.H. (2004).The psychotomimetic effects of intravenous delta-9-tetrahydrocannabinol in healthy individuals: implications for psychosis. Neuropsychopharmacology 29(8), 1558-1572.

Egan M.F., Goldberg T.E., Kolachana B.S., Callicott J.H., Mazzianti C.M., Straub R.E., Goldman D. \& Weinberger D.R. (2001) Effect of COMT val 108/158 genotype on frontal lobe function and risk for schizophrenia. Proceedings of the National Academy of Sciences of the United States of America 98. 6917-6922.

Elphick M.R. \& Egertova M. (2001). The neurobiology and evolution of cannabinoid signalling. Philosophy Transaction Royal Society London 356, 381-408.

Fergusson D.M. \& Horwood L.J.(2000). Does cannabis encourages other forms of illicit drug use? Addiction 95, 505-520.

Fergusson D.M. (2003). Cannabis dependence and psychotic symptoms in young people. Psychological Medicine 33,15-21.

Fergusson D.M., Horwood L.J. \& Ridder E.M.(2005). Tests of causal linkages between cannabis use and psychotic symptoms. Addiction. 100, 3:354-366,

Gorriti M.A., Rodriguez de Fonseca F., Navarro M. \& Palomo T. (1999). Chronic (-)-delta9-tetrahydrocannabinol treatment induces sensitization to the psychomotor effects of amphetamine in rats. European Journal of Pharmacologv 365, 133-142.

Herkenham M., Lynn A.B., Johnson M.R., Melvin L.S., de Costa B.R. \& Rice K.C.. (1991). Characterization and localization of cannabinoid receptorsin rat brain: a quantitative in vitro autoradiographic study. Journal of Neuroscience 11, 563-583.

Iversen L. (2003). Cannabis and the brain. Brain 126,1252-1270.

Lewis C.M., Levinson D.F., Wise L.H., DeLisi L.E., Straub R.E., Hovatta I., Williams N.M., Schwab S.G., Pulver A.E., Faraone S.V., Brzustowicz L.M., Kaufmann C.A.. Garver D.L., Gurling H.M. Lindholm E., Coon H., Moises H.W., Byerley W., Shaw S.H. Mesen A., Sherrington R., O'Neill F.A., Walsh D., Kendler K.S. Ekelund .J, Paunio T., Lonnqvist J.. Peltonen L., O'Donovan M.C., Owen M.J., Wildenauer D.B., Maier W., Nestadt G., Blouin J.L. Antonarakis S.E., Mowry B.J., Silverman J.M., Crowe R.R., Cloninger C.R., Tsuang M.,, Malaspina D., Harkavy-Friedman J.M.,
Svrakic D.M., Bassett A.S., Holcomb J., Kalsi G.. McQuillin A.. Brynjolfson J.. Sigmundsson T., Petursson H. Jazin E., Zoega T. \& Helgason T. (2003). Genome scan meta-analysis of schizophrenia and bipolar disorder, Part II: Schizophrenia. American Journal of Human Genetics 73. 34-48.

Lindqvist T.. Jonsson S. Warkentin S. (2001). Frontal lobe dysfunction in long-term cannabis users. Neturotoxicology' and Teratolog. 23. $437-443$.

Mathers D.C. \& Ghosde A.H. (1992). Cannabis and psychotic illness. British Joumal of Psichiatry 161,648-653.

Miller P.. Lawrie S.M.. Hodges P.R.. Clafferty R., Cosway E.C. \& Johnstone E.C. (2001). Genetic liability. illicit drug use. life stress and psychotic symptoms : preliminary findings from the Edinburgh study of people at high risk for schizophrenia. Social Psychiatry and Psychiatric Epidemiology 36, 338-342.

Murray R.M., Grech A.. Phillips P. \& Johnson S. (2003). What is the relationship between substance abuse and and schizophrenia? In The Epidemiology of Schizophrenia (ed. R.Murray, P.Jones, E. Susser, J.Van Os and Mary Cannon), pp.317-342. Cambridge: Cambridge University Press.

Negrete J.C., KnappW.P.,Douglas D.E. \& SmithW.B. (1986). Cannabis affects the severity of schizophrenia symptoms: results of a clinical survey. Psychological Medicine 16, 515-520.

Rothman K.J. \& Greenland S. (Eds) (1998). Modern Epidemiology, 2. ed. Lippincott-Raven: Philadelphia.

Silva P.A. \& StantonW.R (1996). From Child to Adult: The Dunedin Multidisciplinary Health and Development Study. Auckland: Oxford University Press.

Solowij N., Stephens R.S., Roffman R.A., Babor T., Kadden R., Miller M., Christiansen K., McRee B. \& Vendetti J. (2002). Cognitive functioning of long-term heavy cannabis users seeking treatment. Journal of American Medical Association 287, 1123-1131.

Tanda G., Poitieri F.E. \& Di Chiara G. (1997). Cannabinoid and heroin activation of mesolimbic dopamine transmission by a common UI opioid receptor mechanism. Science 276, 2048-2050.

Thornicroft G.(1990). Cannabis and psychosis. Brifish Journal of Psychiatry 157, 25-33.

Van Ós J., Bak M., Bijl R.V., De Graaf R. \& Verdoux H. (2002). Cannabis use and psychosis: a longitudinal population-based study. American Journal of Epidemiology 156, 319-327.

Verrico C.D., Jentsch J.D. \& Roth R.H. (2003). Persistent and anatomically selective reduction in prefrontal cortical dopamine metabolism after repeated intermittent cannabinoid administration to rats. Syapse 49, 61-66.

Voruganti L., Slomka P., Zabel P., Costa G., So A., Mattar A. \& Awad A.G. (2001). Subjective effects of AMPT-induced dopamine depletion in schizophrenia: correlation between dysphoric responses and striatal $D(2)$ binding ratios on SPECT imaging. Neuropsychopharmacology 25(5), 642-650.

Weinberger D.R., Egan M.F., Bertolino A., Callicott J.H., Mattay V.S., Lipska B.K., Berman K.F. \& Goldberg T.E. (2001) Prefrontal neurons and the genetics of schizophrenia. Biological Psychiary 50, 825-844.

Zammit S., Allebeck P., Andrèasson S., Lundberg I. \& Lewis G. (2002). Self-reported cannabis use as a risk factor for schizophrenia in Swedish conscripts of 1969: historical cohort study. British Medical Joumal 325, 1199-1201. 